\title{
ASSESSING MARKETING AGILITY IN DEVELOPING ECONOMIES: BUSINESS NETWORK IMPLICATIONS, RESEARCH ISSUES AND TANZANIAN CASE STUDY
}

Michael A. Mayo, Kent State University, Kent, OH, U.S.A.

Lawrence J. Marks, Kent State University, Kent, OH, U.S.A.

dx.doi.org/10.18374/IJBS-20-1.2

\begin{abstract}
Competing successfully in the global economy requires firms to develop and manage agile relationships with its network partners to quickly assess and react to changing market conditions. Doing so may be difficult when networks include firms from both developed and developing economies that may not share a common technical/social-cultural background needed to work collaboratively. To anticipate when this may be the case, the following report identifies proxy measures and a process that may be used to assess â€ agility-readiness' of firms operating in a foreign market of interest using Tanzania as an overview example. Managerial implications and recommendations for further research are included to further both the practice and theory development in the area.
\end{abstract}

Keywords: International Business Research, Marketing Agility, Global Business Management, Networked Systems, Developing Economies, Information Communication Technologies, Cultural Values, Tanzania 